\title{
Ammonia Synthesis Using Magnetically Induced Reaction
}

\author{
Noorhana Yahya ${ }^{1, a}$, Poppy Puspitasari ${ }^{2, b}$, Nor Hasifah Noordin ${ }^{3, c}$ \\ ${ }^{1}$ Fundamental and Applied Sciences Department, UniversitiTeknologi PETRONAS \\ ${ }^{2}$ Electrical and Electronics Engineering Department, UniversitiTeknologi PETRONAS \\ ${ }^{3}$ Chemical Engineering Department, UniversitiTeknologi PETRONAS \\ Bandar Seri Iskandar, 31750, Tronoh, Perak DaruIRidzuan, Malaysia
}

anoorhana_yahya@petronas.com.my , ’povopivi@gmail.com, norhasifah.noordin@gmail.com

Keywords: ammonia, magnetic induction, yield, nanocatalyst

\begin{abstract}
Ammonia production is a high energy and capital intensive industry as it requires high temperature $\left(400-500^{\circ} \mathrm{C}\right)$ and high pressure $(150-300 \mathrm{bar})$ for its daily operations. By introducing nano-catalyst with the new concept of micro-reactor with applied magnetic field induction, the catalytic activity can be induced and the output can be enhanced. Magneto-dynamics will be introduced in the ammonia production process in order to replace the concept of thermodynamics in the Haber Bosch process. The nanocatalysts $\left(\mathrm{Y}_{3} \mathrm{Fe}_{5} \mathrm{O}_{12}, \mathrm{Fe}_{2} \mathrm{O}_{3}, \mathrm{MnO}, \mathrm{Mn}_{0.8} \mathrm{Zn}_{0.2} \mathrm{Fe}_{2} \mathrm{O}_{4}\right)$ have been reduced by using the temperature reduction method (TPR). The $\mathrm{Y}_{3} \mathrm{Fe}_{5} \mathrm{O}_{12}$ (YIG) catalyst with magnetic induction produced $242.56 \mu \mathrm{mol} / \mathrm{h}$.g-cat output of ammonia which is $2 \%$ much higher than ammonia synthesis without magnetic induction $(237.52 \mu \mathrm{mol} / \mathrm{g} . \mathrm{h})$. The ammonia output based on the magnetic induction method at a temperature of $0^{\circ} \mathrm{C}$ is $242.56 \mu \mathrm{mole} / \mathrm{h}$.g-cat which is $0.90 \%$ higher than the synthesis at $25^{\circ} \mathrm{C}$ temperature $(240.4 \mu \mathrm{mol} / \mathrm{g} . \mathrm{h})$. The ammonia output at $0.2 \mathrm{Tesla}$ is $249.04 \mu \mathrm{mole} / \mathrm{h}$.g-cat which is higher $2.6 \%$ than the output at 0.1 Tesla which is $242.56 \mu \mathrm{mol} / \mathrm{g}$.h. It is proven that the higher the applied magnetic field is, the more effective the catalytic activity will be as a better alignment of the electron spin of the catalyst occurs and enhances the adsorption and desorption process. $\mathrm{Y}_{3} \mathrm{Fe}_{5} \mathrm{O}_{12}$ (YIG) shows the best catalytic reaction followed by $\mathrm{Fe}_{2} \mathrm{O}_{3}$ (hematite) and $\mathrm{MnO}$ (manganese oxide). By this new route, synthesis of ammonia at low temperature is realized and offers ammonia producers an economic advantage compared to the classical routes.
\end{abstract}

\section{Introduction}

In the current scenario, ammonia and urea industry is rising significantly as new markets for biofuel and $\mathrm{NO}_{\mathrm{x}}$ abatement emerges while existing markets are challenged. Capital and logistic cost rises have altered the business decision but despite this upheaval and uncertainty, growth has continued apace [1]. The current technology of ammonia production is only capable to generate a small output from a huge amount of feedstock which is only about $10 \%$ to $20 \%$ of ammonia output with high capital and energy intensive consumption. Many ammonia plants struggle with high feedstock prices, high maintenance and high energy consumption for the plant in order to maintain at high temperature and high pressure [2].

In order to overcome these drawbacks, magnetic nanotechnology is seen as an excellent solution by introducing nano-catalyst applied with the new concept of magnetic induction to induce the catalytic activity and at the same time enhancing the production output. By applying the concept from the First Law of Thermodynamics that energy cannot be created or destroyed but can be converted from one form to another, magneto-dynamic has been introduced to replace the concept of thermodynamics from the Haber Bosch process which require the production of ammonia at high temperature and high pressure. The objective of this research is to introduce the application of conversion of magnetic energy to chemical energy instead of conversion of heat and mechanical energy to chemical energy in ammonia production. 


\section{Ammonia Synthesis}

The reaction of ammonia synthesis is reversible and exothermic [3]:

$$
\mathrm{N}_{2(\mathrm{~g})}+3 \mathrm{H}_{2(\mathrm{~g})} \leftarrow \rightarrow 2 \mathrm{NH}_{3(\mathrm{~g})} \quad+92.4 \mathrm{~kJ}
$$

The main role of the ammonia catalyst is to dissociate the N-N bond. With the presence of magnetic induction, the $\mathrm{N}_{2}$ bond will be dissociated more easily through the adsorption and desorption process. The adsorption process in the ammonia synthesis is an essential process where the reactant molecules $\left(\mathrm{H}_{2}\right.$ and $\mathrm{N}_{2}$ gas) adhere to the surface of the metal catalyst and go through a physicsorption and chemical chemi-sorption process. As the reactant gases flow into the reaction medium, they will be firstly adsorbed to the metal surfaces by physic-sorption and at this stage, a van der Waals interaction between the reactants and metal surfaces occurs. The enthalpy change due to adsorption $\left(\mathrm{DH}_{\text {ads }}\right)$ is $5-50 \mathrm{~kJ} / \mathrm{mole}$ [3]. This enthalpy change is insufficient for the bond breaking to occur. Hence, physisorbed molecules are retained and then multilayer adsorption would occur. Multilayer adsorption is a phenomenon where the adsorption surface accommodates more than one layer of molecules, and not all adsorbed molecules are in direct contact with the surface of the metal.

Chemical adsorption is a process of sharing or exchanging electrons between the reactants and the partially occupied d-orbital of iron metal forming a chemical bond. The chemisorption enthalpy is $50-500 \mathrm{~kJ} / \mathrm{mole}$ which is greater than for physic-sorption. Theoretically, when the nitrogen molecules are chemically adsorbed, the triple bond which ties two nitrogen atoms together is favored to donate their electron to the partially occupied d-orbital of the iron metal. This is usually referred to as sigma (s) donation which forms a strong chemical bond which results in a shorter distance between the adsorb nitrogen molecules and iron metal surfaces. Iron metal has four unpaired electrons (d6) in the d-orbital and needs four additional electrons to be stabilized. Because of this, the excess electron will be donated back to the empty pie ( $\mathrm{p}^{*}$ ) orbital's of nitrogen molecules. This process is known as p-back donation. In consequence, the N-N bond is lengthened and weakens. Thus, the nitrogen molecules will be separated and fragmented on the iron metal surface to form monolayer adsorption. At this stage, all the adsorbed atoms are in contact with the surface layer of the adsorbent $[3,4]$.

Then, the migration process involves the movement of chemisorbed single atoms and reacts among each other to form the product, i.e. in this case ammonia. It happens because the bonding between chemisorbed molecules and the iron metal surfaces provides a thermodynamic driving force for the release of atoms so that the migration can be accomplished [5]. Once the product is formed, the intermediate strength of surface bonds allows desorption of products $\left(\mathrm{NH}_{3}\right)$. So it leaves free active sites for the incoming hydrogen and nitrogen reactants molecules to be adsorbed and react on the iron metal surfaces. Using a nano-sized catalyst is attractive due to its high surface area leading to its active site for the physi- and chemi-sorption process while the magnetic field is applied. This will contribute to the alignment of the electron spin of the iron metal and provides a better electron exchange between the catalyst and the reactant gases.

\section{Magneto-Thermodynamic Effect in Chemical Reaction}

This subsection is concerned with the magnetic field effects (MFEs) on the chemical equilibrium and related phenomena. ${ }^{1}$ Besides the equilibrium constant, a chemical reaction is accompanied by important thermodynamic quantities, such as the heat, the free energy and the entropy of reaction. Let us consider the chemical system in which $k$ kinds of ideal gasses are reacting with each other at the stoichiometric coefficients $v_{i}(i=1 \sim k)$ under the influence of a magnetic field. Then, the condition of a chemical equilibrium is written by, 


$$
\sum_{i=1}^{k} v_{i} \mu_{i}=0
$$

Where the chemical potential of the $i$-th gas consists of the non-magnetic term $\mu^{(0)} i$ and the magnetic term $\mu\left({ }^{\mathrm{m})} i\right.$ as,

$$
\mu_{i}=\mu_{i}^{(0)}+\mu_{i}^{(m)}=\mu_{i}^{*}+R T \ln \frac{P_{i}}{P^{*}}-\int_{0}^{H} \mu_{0} m_{i} d H
$$

Where $\mu_{i}^{*}$ is the standard chemical potential at temperature $T$ and the standard pressure $P *$ in a zero magnetic field. $P_{i}$ and $\mathrm{m}_{i}$ are the partial pressure and the molar magnetization for the $i$-th component. $\mu_{0}$ is the permeability of the vacuum. The integration must be done with respect to the magnetic field strength $H$ at constant temperature $T$. The equilibrium constant $K_{\mathrm{p}}$ is derived from Eqs.(2) and(3) as,

$$
\ln K_{p}=\sum_{i=1}^{k} v_{i} \ln \frac{P_{i}}{P^{*}}=-\frac{1}{R T} \sum_{i=1}^{k} v_{i}\left(\mu_{i}^{*}+\mu_{i}^{(m)}\right)
$$

Equation (4) leads to the magnetic field-induced change in the equilibrium constant.

$$
\ln K_{P}^{[H]}-\ln K_{P}^{[0]}=-\frac{1}{R T}\left(-\sum_{i=1}^{k} v_{i} \int_{0}^{H} \mu_{0} m_{i} d H\right)=-\frac{1}{R T} g^{(m)}
$$

Where ${ }^{[\mathrm{H}]}$ and ${ }^{[0]}$ are the equilibrium constant in the magnetic field and in the zero fields, respectively. Below similar notations are used for other thermodynamic quantities. $g^{(\mathrm{m})}$ is the magnetic free energy change per unit reaction. Moreover, the heat of reaction $\Delta H^{0}$, the free energy of reaction $\Delta G^{0}$ and the entropy of reaction $\Delta S^{0}$ are a function of temperature $T$ and magnetic field strength $H$, too. In this paper we omit the ${ }^{[0]}$ form the notation for simplification. Using the standard theory of chemical thermodynamics yields the magnetic field-induced changes in these thermodynamic quantities as

$$
\begin{gathered}
\Delta H^{[H]}-\Delta H^{[0]}=g^{(m)}-T \frac{d}{d T} g^{(m)} \\
\Delta G^{[H]}-\Delta G^{[0]}=g^{(m)} \\
\Delta S^{[H]}-\Delta S^{[0]}=-\frac{d}{d T} g^{(m)}
\end{gathered}
$$

Equations (5) to (8) are the general formulae for the magneto-thermodynamic effects in chemical reactions. This magneto-thermodynamic formulation is applicable to all of the MFEs in chemical reactions [7].

\section{Magnetization versus Temperature}

The influence of temperature on magnetic materials can be determinate in the magnetic properties of those materials. Rising the temperature of a solid will result in the increase of the thermal vibrations of atoms and with this the atomic magnetic moments are free to rotate. Due to this phenomenon, the atoms tend to randomize the directions of any moments that may be aligned [6]. With increasing temperature, the saturation magnetization diminishes gradually and abruptly drops to zero at the Curie temperature $(T)$.

At temperatures below the Curie point the magnetic moments are partially aligned within magnetic domains in ferromagnetic materials. As the temperature is increased from below the Curie point, thermal fluctuations increasingly destroy this alignment, until the net magnetization becomes zero at and above the Curie point. Above the Curie point, the material is purely paramagnetic. At temperatures below the Curie point, an applied magnetic field has a paramagnetic effect on the magnetization, but the combination of para-magnetism with ferromagnetism leads to the magnetization following a hysteresis curve with the applied field strength. Table 1 shows some examples of Curie temperature for various materials 
Table 1: Curie temperature of various materials [6]

\begin{tabular}{|c|c|}
\hline Material & Curie Temperature (K) \\
\hline Magnetite & 858 \\
\hline Iron & 1043 \\
\hline $\mathrm{Y}_{3} \mathrm{Fe}_{5} \mathrm{O}_{12}(\mathrm{YIG})$ & 550 \\
\hline Hematite & 1000 \\
\hline Nickel & 631 \\
\hline Cobalt & 1393 \\
\hline
\end{tabular}

\section{Methodology}

Effects of changing the variable on the process response is evaluated in the following see Fig. 1.

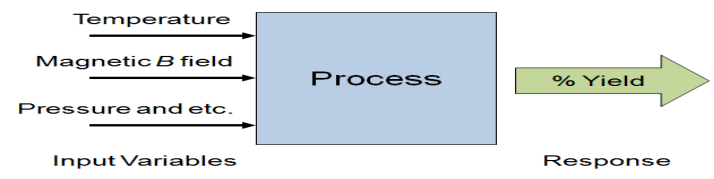

Figure 1. Changing Variable on the Ammonia Synthesis

The following types of experiments were done, see Fig. 2:

i. Synthesis of ammonia at different conditions with and without magnetic induction to understand the effect of the magnetic field on the catalytic activity

ii. Synthesis of ammonia at different temperature that is $0^{\circ} \mathrm{C}$ and $25^{\circ} \mathrm{C}$ using $\mathrm{YIG}\left(\mathrm{Y}_{3} \mathrm{Fe}_{5} \mathrm{O}_{12}\right)$ catalyst to know the effect of temperature on the electron spin alignment

iii. Synthesis of ammonia by using different types of catalysts, i.e.hematite $\left(\mathrm{Fe}_{2} \mathrm{O}_{3}\right)$, magnetite $\left(\mathrm{Fe}_{3} \mathrm{O}_{4}\right)$, manganese zinc ferrite $\left(\mathrm{Mn}_{0.8} \mathrm{Zn}_{0.2} \mathrm{Fe}_{2} \mathrm{O}_{4}\right)$, YIG $\left(\mathrm{Y}_{3} \mathrm{Fe}_{5} \mathrm{O}_{12}\right)$ and manganese oxide $(\mathrm{MnO})$ at $0^{\circ} \mathrm{C}$

iv. Synthesis of ammonia at different magnetic strength (0.1T and $0.2 \mathrm{~T})$ in micro-reactor (Fig. 3)

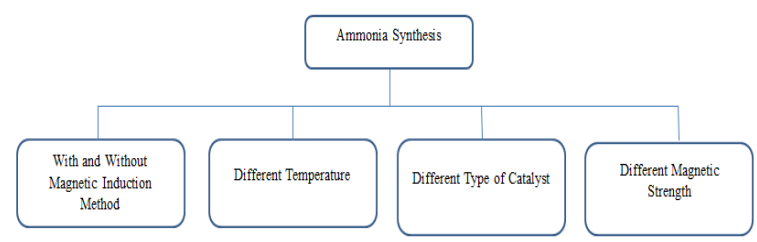

Figure 2: Types of conducted experiments.

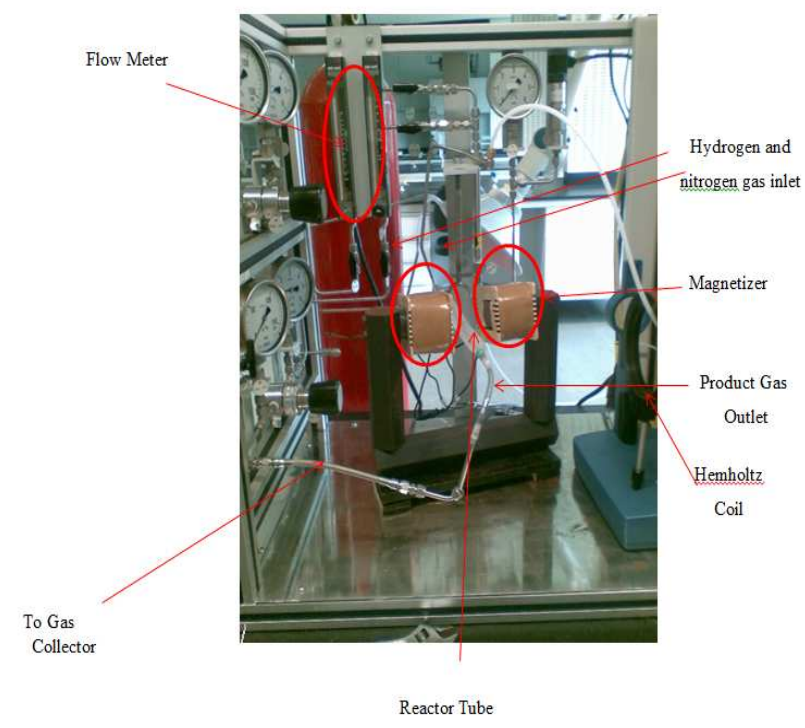

Figure 3: Ammonia micro-reactor. 


\section{Result and discussion}

\section{Temperature Program Reduction (TPR) Result}

The reduction of various iron oxides in hydrogen and carbon monoxide atmospheres has been investigated by temperature programmed reduction $\left(\mathrm{TPR}_{\mathrm{H} 2}\right)$. Five different compounds were characterized: hematite $\alpha-\mathrm{Fe}_{2} \mathrm{O}_{3}$, magnetite $\mathrm{Fe}_{3} \mathrm{O}_{4}$, manganese oxide $\mathrm{MnO}$, Manganese Zinc Ferrite $\mathrm{Mn}_{0.8} \mathrm{Zn}_{0.2} \mathrm{Fe}_{2} \mathrm{O}_{4}$, and $\mathrm{YIG} \mathrm{Y}_{3} \mathrm{Fe}_{5} \mathrm{O}_{12}$ nanocatalyst. The reduction process takes place after accompanying dehydration up to $1000^{\circ} \mathrm{C}$.

\begin{tabular}{|c|c|c|c|}
\hline TPR Results & $\begin{array}{l}\text { The reduction } \\
\text { mechanism } \\
{[8,9,10,11] \text { : }}\end{array}$ & $\begin{array}{l}\text { Tempera } \\
\text { ture }\left({ }^{\circ} \mathrm{C}\right)\end{array}$ & Ref. \\
\hline 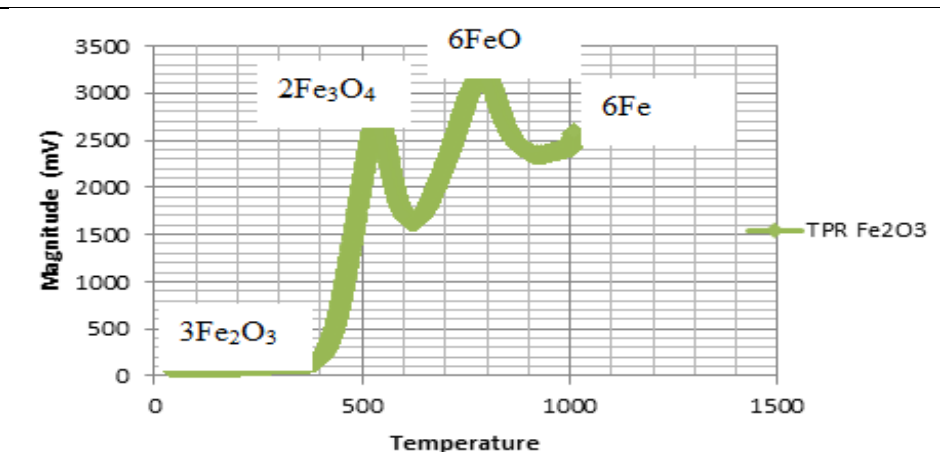 & $\begin{array}{l}3 \mathrm{Fe}_{2} \mathrm{O}_{3} \rightarrow 2 \mathrm{Fe}_{3} \mathrm{O}_{4} \\
2 \mathrm{Fe}_{3} \mathrm{O}_{4} \rightarrow 6 \mathrm{FeO} \\
6 \mathrm{FeO} \rightarrow 6 \mathrm{Fe}\end{array}$ & $\begin{array}{l}250-570 \\
570-795 \\
795- \\
1025\end{array}$ & [8] \\
\hline 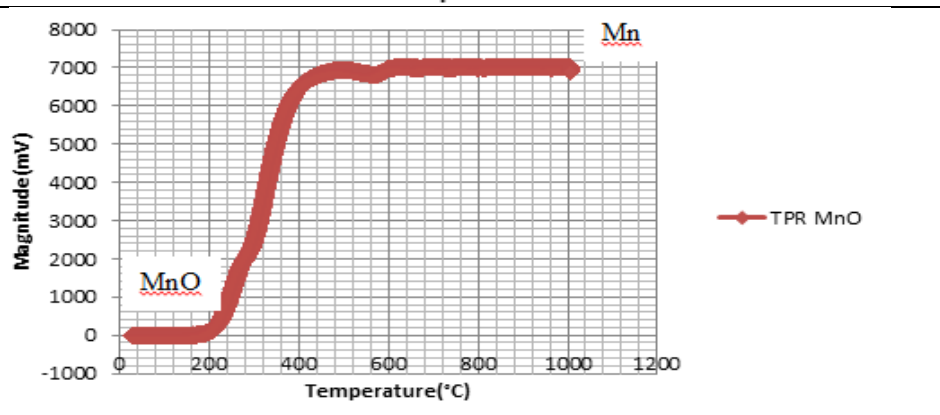 & $\begin{array}{l}\mathrm{MnO}+\mathrm{H}_{2} \rightarrow \mathrm{Mn} \\
\mathrm{Mn}\end{array}$ & $\begin{array}{l}200-475 \\
475- \\
1000\end{array}$ & {$[9,10]$} \\
\hline 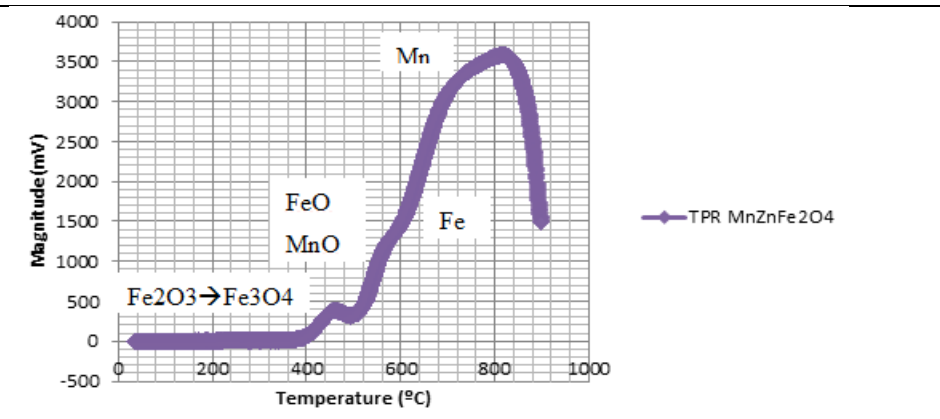 & $\begin{array}{l}\mathrm{Fe}_{3} \mathrm{O}_{4} \rightarrow \mathrm{Fe}_{2} \mathrm{O}_{3} \\
\mathrm{MnZnO} \\
\mathrm{Fe}_{3} \mathrm{O}_{4} \rightarrow \mathrm{FeO} \\
\mathrm{FeO} \rightarrow \mathrm{Fe} \\
\mathrm{MnZnO} \rightarrow \mathrm{Mn}\end{array}$ & $\begin{array}{l}273-350 \\
463 \\
540 \\
650 \\
736\end{array}$ & [11] \\
\hline 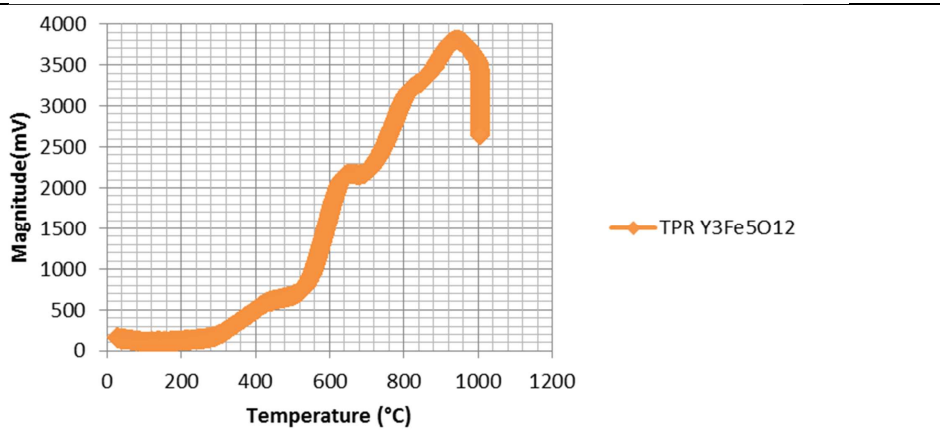 & $\begin{array}{l}\mathrm{Y}_{3} \mathrm{Fe}_{5} \mathrm{O}_{12} \rightarrow \\
\mathrm{FeO}+\mathrm{YO}_{2}+\mathrm{O}_{2} \\
\mathrm{FeO} \rightarrow \mathrm{Fe} \\
\mathrm{YO}_{2} \rightarrow \mathrm{Y}_{3}\end{array}$ & $\begin{array}{l}273-350 \\
795 \\
960\end{array}$ & [13] \\
\hline
\end{tabular}

Figure 4: TPR Profile of $\mathrm{Fe}_{2} \mathrm{O}_{3}$ (Hematite) Nanocatalyst. 


\section{Ammonia Synthesis at $0^{\circ}$ C Temperature with and without Magnetic Induction Method}

The syntheses of ammonia were conducted at a temperature of $0^{\circ} \mathrm{C}$ using $\mathrm{Y}_{3} \mathrm{Fe}_{5} \mathrm{O}_{12}$ (YIG) and $\mathrm{Fe}_{2} \mathrm{O}_{3}$ (Hematite) nanocatalyst. Firstly, the reactant gases were reacted with the $\mathrm{Y}_{3} \mathrm{Fe}_{5} \mathrm{O}_{12}$ (YIG) nanocatalyst by the magnetic induction method (MIM) applied at 0.1 Tesla for duration of 30 minutes. The experiment was repeated by reacting the reactant gases with the YIG nanocatalyst without application of MIM. The whole experiment then is repeated by using the $\mathrm{Fe}_{2} \mathrm{O}_{3}$ (Hematite) nanocatalyst.

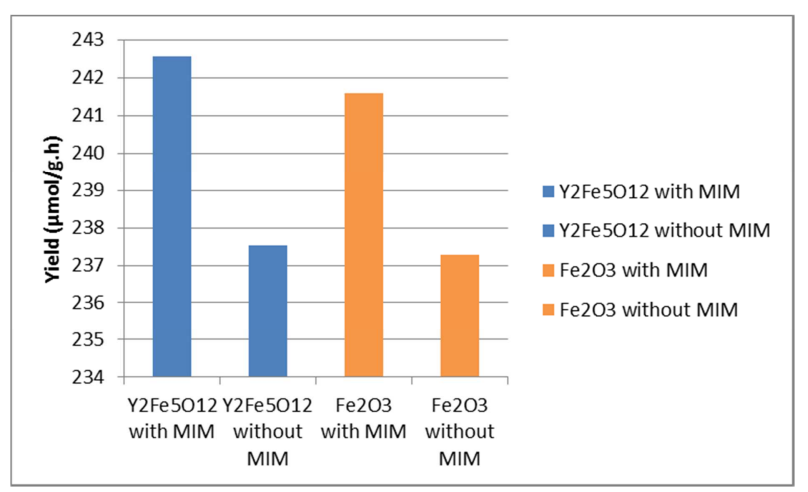

Figure 5: Output of ammonia at different magnetic induction conditions.

Figure 5 shows that the output of the ammonia synthesis by using the $\mathrm{Y}_{3} \mathrm{Fe}_{5} \mathrm{O}_{12}$ (YIG) nanocatalyst with MIM is $242.56 \mu \mathrm{mole} / \mathrm{h}$.g-cat while without MIM it is $237.52 \mu \mathrm{mole} / \mathrm{h}$.g-cat. On the other hand, the output of the ammonia synthesis by the using $\mathrm{Fe}_{2} \mathrm{O}_{3}$ (Hematite) nanocatalyst with MIM is $241.60 \mu \mathrm{mole} / \mathrm{h}$.g-cat while without MIM it is $237.28 \mu \mathrm{mole} / \mathrm{h} . \mathrm{g}$-cat. The result clearly shows that the difference between the reaction with and without MIM is $2 \%$ and $1.8 \%$ for YIG and Hematite nanocatalyst, respectively. The reaction with magnetic induction is much higher than the reaction without magnetic induction since the presence of the magnetic induction forces the electron spin to align while without magnetic induction, the electron spin is random and the reaction will be hard to occur. Magnetic fields can alter the rate, output, or product distribution of chemical reactions [12].

\section{Ammonia Synthesis Using Different Types of Nanocatalysts}

This part is about the synthesis of ammonia using different types of nanocatalysts which are $\mathrm{Y}_{3} \mathrm{Fe}_{5} \mathrm{O}_{12}$ (YIG), $\mathrm{Mn}_{0.8} \mathrm{Zn}_{0.2} \mathrm{Fe}_{2} \mathrm{O}_{4}$ (Manganese Zinc Ferrite), $\mathrm{Fe}_{2} \mathrm{O}_{3}$ (Hematite), MnO (Manganese Oxide) and last but not least $\mathrm{Fe}_{3} \mathrm{O}_{4}$ (Magnetite). The syntheses were done at a temperature of $0^{\circ} \mathrm{C}$ with the magnetic induction method at 0.1 Tesla.

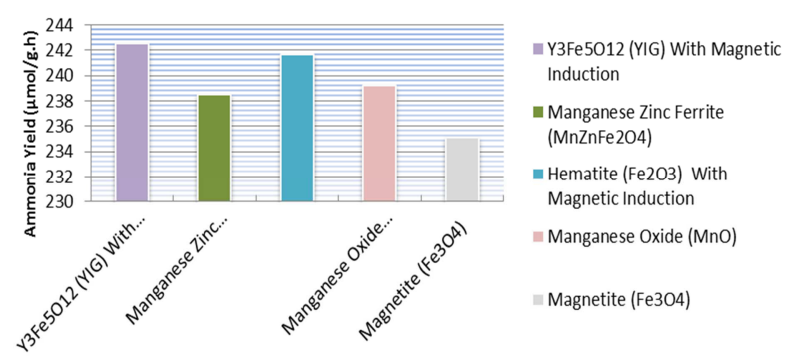

Figure 6: Yield of Ammonia by Using Different Type of Catalyst

Figure 6 shows that the outcome ofthe ammonia synthesis by using $\mathrm{Y}_{3} \mathrm{Fe}_{5} \mathrm{O}_{12}$ (YIG) is the highest (242.56 $\mu \mathrm{mol} / \mathrm{g}$-cat.h) followed by Hematite $\left(\mathrm{Fe}_{2} \mathrm{O}_{3}\right)$ which is $241.656 \mu \mathrm{mol} / \mathrm{g} . \mathrm{h}$, Manganese Oxide $(\mathrm{MnO})$ which is $239.256 \mu \mathrm{mol} / \mathrm{g} . \mathrm{h}$, Manganese Zinc Ferrite $\left(\mathrm{MnZnFe}_{2} \mathrm{O}_{4}\right)$ which is 238.4856 $\mu \mathrm{mole} / \mathrm{h} . \mathrm{g}$-cat and last but not least Magnetite $\left(\mathrm{Fe}_{3} \mathrm{O}_{4}\right)$ which is $235.1256 \mu \mathrm{mol} / \mathrm{g} . \mathrm{h}$. 


\section{Ammonia Synthesis at Different Magnetic Strengths}

In this experiment, two types of experiments were done by using a permanent magnet (MIM) and a soft magnet (Hemholtz Coil). For the first experiment, the ammonia synthesis was done by using the $\mathrm{Fe}_{2} \mathrm{O}_{3}$ (Hematite) nanocatalyst at $0^{\circ} \mathrm{C}$ temperature with a magnetic induction strength of 0.1 Tesla. Then the experiment was repeated by using magnetic induction at strength of 0.2 Tesla.

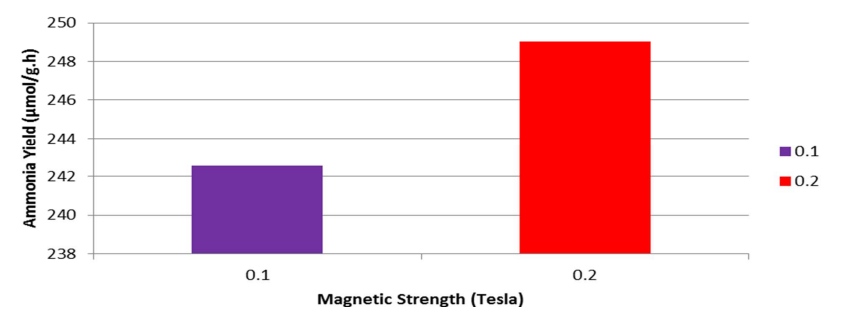

Figure 7: Yield of ammonia at different magnetic strengths by using MIM.

Figure 7 shows that the ammonia synthesis at 0.2 Tesla $(249.04 \mu \mathrm{mol} / \mathrm{g} . \mathrm{h})$ is $3 \%$ higher than the ammonia synthesis at 0.1 Tesla $(242.56 \mu \mathrm{mol} / \mathrm{g} . \mathrm{h})$.

For the second experiment, the Helmholtz Coil was added at the inlet of the reactant gases stream in order to ease the hydrogen molecules to break the bond before attaching to the catalyst. The reaction was done at $25^{\circ} \mathrm{C}$ temperature using the $\mathrm{MnO}$ nanocatalyst.

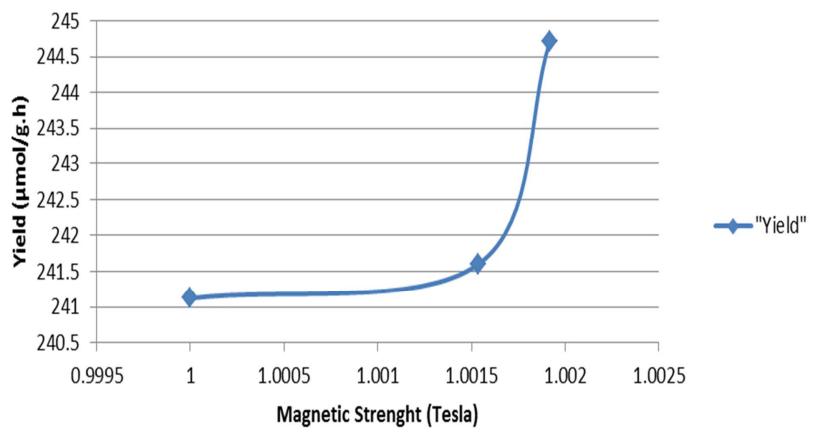

Figure 8: Output of ammonia at different magnetic strengths with addition of Helmholtz Coils.

Figure 8 shows that the ammonia output without addition of the Helmholtz Coil is 241.12 $\mu$ mole/h.g-cat while the output increases significantly after addition of a pair of Helmholtz Coils (241.6 $\mu$ mole/g.h) and six pairs of Helmholtz Coils $(244.72 \mu$ mole/g.h). As shown in the graph, the output increases significantly when the magnetic strength is increased. Thus proves that a magnetic field can enhance the catalytic induction and enhance the output of the reaction.

\section{Conclusion}

It is concluded that the presence of magnetic induction could enhance the output of the ammonia production. The output of the ammonia synthesis with magnetic induction using the $\mathrm{Y}_{3} \mathrm{Fe}_{5} \mathrm{O}_{12}$ (YIG) catalyst is $242.56 \mu \mathrm{mole} / \mathrm{h}$.g-cat which is $2 \%$ higher than the output of the ammonia synthesis without magnetic induction using the $\mathrm{Y}_{3} \mathrm{Fe}_{5} \mathrm{O}_{12}$ (YIG) catalyst which is only $237.52 \mu \mathrm{mole} / \mathrm{h}$.g-cat. At temperatures below the Curie point, the magnetic moments are partially aligned within magnetic domains in ferromagnetic materials. As the temperature is increased, thermal fluctuations increasingly destroy this alignment. The experiment of ammonia synthesis at different temperatures of $0^{\circ} \mathrm{C}$ and $25^{\circ} \mathrm{C}$ proves that the ammonia output is higher at the temperature of $0^{\circ} \mathrm{C}$ which is 242.56 $\mu \mathrm{mole} / \mathrm{h}$.g-cat while $240.4 \mu$ mole $/ \mathrm{h}$.g-cat at $25^{\circ} \mathrm{C}$. The synthesis of ammonia at different magnetic strengths shows that the output at $0.2 \mathrm{~T}$ is higher than the output at $0.1 \mathrm{~T}$ which is 249.04 
$\mu$ mole/h.g-cat and $242.56 \mu$ mole/h.g-cat, respectively. Addition of Helmholtz Coils at the inlet of the reactant gases stream also contributes to the output enhancement since the ammonia synthesis output is $244.72 \mu \mathrm{mole} / \mathrm{g}$.h with six pairs of Helmholtz Coils while the output is $241.12 \mu \mathrm{mole} / \mathrm{g} . \mathrm{h}$ without Helmholtz Coil. These results prove that the higher the applied magnetic field is, the more effective the catalytic activity will be. Catalytic reactions giving emphasis on different types of catalysts were also reviewed in this work. $\mathrm{Y}_{3} \mathrm{Fe}_{5} \mathrm{O}_{12}$ (YIG) shows the best catalytic reaction (242.56 $\mu \mathrm{mol} / \mathrm{g}$-cat.h) followed by $\mathrm{Fe}_{2} \mathrm{O}_{3}$ (Hematite) and $\mathrm{MnO}$ (Manganese Oxide) which is 241.656 $\mu \mathrm{mol} / \mathrm{g} . \mathrm{h}$ and $239.256 \mu \mathrm{mol} / \mathrm{g} . \mathrm{h}$, respectively.

\section{References}

[1] Chemsystems. Prospectus (September 2009/2010). (2011). Ammonia. Retrieved November 09,2011 from www.chemsystem.com

[2] Ammonia and Urea Strategic Business Analysis. Retrieved April 20, 2011 from, www.chemsytem.com

[3] C. M. Roebuck (2004),Excel HSC Chemistry, $1^{\text {st }}$ ed. New South Wales, Australia: Pascal Press, pp. 35-41

[4] K.N. Whitten, R.E. Davis, M.L. Peck, G.G. Stanley, (2003), General Chemistry Thomson Brookscole, 7, pp. 713-720

[5] G.A. Samorjai (1994), Introduction to Surface Chemistry and Catalysis, $1^{\text {st }}$ ed. Hoboken, New Jersey: Wiley Interscience

[6] W. Rarog-Pilecka, E. Miskiewics, D. Szmigiel, Z. Kowalczyk, (2008), Journal of Catalysis Vol. 231, pp. 11-19

[7] Richardson, James T. (2009). Journal of Applied Catalyst. Issue 3, (pp.1781-1786)

[8] W.K. Jozwiak, E. Kaczmarek. (2007). Applied Catalysis A: General Vol. 326, Issue 1 (pp. 1727)

[9] M.A. Ullmann1, A. da C. Schneid, D. Bianchini. Thermal catalytic properties of Mn supported on porous silica nanostructures. Article from Universidade Federal de Pelotas, Brasil.

[10] Oliveira, L.C.A., Fabris, J.D., Rios, R.R.V.A., Mussel, W.N., Lago, R.M. (2004): Appl. Catal. A Gen. 259, (pp.253-259)

[11] F.G. Duran, B. P. Barbero, L.E. Cadus, C. Rojas, M.A. Centeno, J. A. Odriozola (2009), Applied Catalyst B: Environmental, vol. 92, pp. 194-201.

[12] C.T. Rodgers (2009). Pure and Applied Chemistryvol.81, (pp.19-43)

[13] O.Yu. Goncharov, Yu.P. Vorobiov and O.V. Carban (1997), Journal of Physics IV France 07 C1.pp. 185-186. DOI: 10.1051/jp4:1997168. 